\title{
APRENDER VERSUS ENSINAR: CHARLES SANDERS PEIRCE E A UNIVERSIDADE AMERICANA DO FINAL DO SÉCULO XIX.*
}

\author{
Lauro Frederico Barbosa da SILVEIRA **
}

\begin{abstract}
RESUMO: A produção científica e filosófica de Charles Sanders PEIRCE (1839-1914), exigindo como critério para o trabalho intelectual e para a conduta da vida do pensador o absoluto rigor na construção dos conceitos e a estrita verificação experimental, teve por conseqüência desvincular o trabalho científico e filosófico de qualquer função apologética. A afirmação de que todo conhecimento do mundo da experiência e mesmo daquele elaborado pela matemática é intrinsecamente provável e falível se opôs a todo e qualquer dogmatismo e mesmo ao "a priori" de tradição Kantiana. O interesse pela teoria evolucionista e a coerência inabalável da filosofia e das atitudes de PEIRCE, como prof essor e pesquisador, encontraram profunda resistência no meio universitário e editorial de seu tempo. Num momento de grave crise na Universidade norte-americana, decorrente das transformações econômicas e políticas ocorridas com a guerra da Secessão (1861-1865), o posicionamento de PEIRCE contribuiu muito provavelmente para sua demissão como prof essor das Universidades de Harvard e de John Hopkins; para dificultar a publicação de seus escritos e para seu total isolamento nos últimos anos de vida.
\end{abstract}

UNITERMOS: Charles Sanders PEIRCE; Universidade de Harvard; Universidade de John Hopkins; Morrill Act; Thomas Huxey; pragmatismo; falibilismo; evolucionismo; filosofia; ensino universitário.

Em 1884 o contrato de trabalho de Charles Sanders PEIRCE $\left({ }^{b}\right)$ na recém fundada Universidade de John Hopkins foi "sumariamente cancelado em circunstâncias obscuras"' $(6$, p. 1430) não mais tendo conseguido manter qualquer posto acadêmico, isto em prejuízo, segundo NAGEL (5, p. 185-186), do avanço de história da filosofia posterior: do avanço dos estudos de lógica e de filosofia. PEIRCE tinha então quarenta e quatro anos.

Já nesse momento teria sido afastado da Universidade de Harvard, onde se formara e à qual sempre se refere. Veio, finalmente a se desligar do trabalho em ciência aplicada no Coast and Geodetic Survey Department (1891) onde trabalhou durante vinte anos, instituição pela qual chegou a representar os Estados Unidos em conferências científicas internacionais. As razões deste desligamento são novamente descritas como pouco esclarecidas (2, p. 18) mas que tiveram na base exigências metodológicas reivindicadas por PEIRCE do organismo em que trabalhava. Com tal afastamento termina sua carreira científica ativa, sobrando ao filósofo, descontados os últimos quatro anos de insuportável doença física, dezenove anos de quase completo ostracismo no qual

* Este texto foi originalmente levado a público no simpósio sobre $O$ Progresso da Ciência e Educação: Incursðes na questão da Universidade, da Filosofia e do Poder, durante a 32. ${ }^{\text {a }}$ Reunião Anual da SBPC, Rio de Janeiro no dia 8 de julho de 1980.

* Departamento de Filosofia - Faculdade de Educação, Ciências Sociais e da Documentação - UNESP - 17.500 - Marília - SP. 
SILVEIRA, L.F.B. da - Aprender versus ensinar: Charles Sanders Peirce e a universiciade americana do final do século XIX. Trans/Form/Ação, São Paulo, 5: 77-84, 1982.

muito produziu mas não encontrou sequer alguém que publicasse os escritos.

Denunciam, como freqüentemente acontece aos pensadores que não encontram estabilidade em instituições educacionais e congêneres, a dificuldade de convívio social do autor e a falta de senso de organização e de responsabilidade como as causas de seus fracassos profissionais. Da Universidade de Harvard, há um aspecto significativo em sua demissão: o fato de ter se separado de sua primeira mulher Harriet Melusina FAY, membro de tradicional família da Nova Inglaterra. Para seu afastamento da Universidade de John Hopkins, não faltou a suspeita de impiedade, senão de ateísmo, que pesava desde a fundação da Universidade (1876) sobre a cabeça de vários de seus mais ilustres mestres $(7$, p. 1427-1431).

Não se pode, porém, considerar tais explicações de motivo como decisivas. Se bem que o trato com PEIRCE não pareça ter sido fácil, pois disto testemunham sua primeira mulher, seu amigo William JAMES, assim como o irmão deste último, Henry JAMES, quando conviveu com PEIRCE em Paris (2, p. 16, 18, 19; 4, p. $12,13)$, foi PEIRCE capaz de, como professor, formar um grupo de excelentes discípulos que reconheceram a profunda importância do ensino que com ele receberam. Entre estes, estaria Josiah ROYCE, John DEWEY e Joseph JASTROW. Quanto a uma incompatibilidade radical que decorresse da filosofia peirceana com a doutrina cristã tal como a professada pelas igrejas Congregacionista, mantenedora da Universidade de Harvard, ou Presbiteriana, orientadora doutrinária da Universidade de John Hopkins, nada parece constituir uma prova fragrante: PEIRCE não questiona a fé e a piedade, coloca-se estritamente no interior do discurso científico e filosófico, inclusive encaminhando-se progressivamente pelas sendas do realismo crítico, coroando seu discurso na construção, se bem que estri- tamente hipotética, de uma metafísica que incorpora a própria instância divina.

A incompatibilidade de PEIRCE com a instituição Universitária, com o interesse dos editores e, posteriormente, com o próprio Coast and Geodetic Survey Department, parece ter sido mais prof unda.

A chave para sua descoberta talvez se encóntre na crítica da qual o autor teria sido objeto, crítica esta que, no entanto, ele reconheceu como o único grande elogio que recebera: "ele era um pensador que não parecia absolutamente seguro de suas próprias conclusões"' $(3, \mathrm{I}, 10)$. É este, com ef eito, o grande traço característico da filosofia peirceana e é contra a pretensa segurança do ensino da filosofia na Universidade de Harvard, que PEIRCE tece suas críticas ao se ref erir à instituição de ensino de seu tempo (3, I, 76-77: I, $650 ; \mathrm{V}, 582-585)$.

As instituiçð̃es de ensino superior mais tradicionais norte-americanas, aquelas que foram fundadas pelas primeiras comunidades que se instalaram na Nova Inglaterra desde a primeira metade do século XVII (Harvard, Yale) e mesmo posteriormente, como a Universidade de John Hopkins em Baltimore, Maryland, eram marcadas pela necessidade de formar profissionalmente a juventude sob a orientação da confissão religiosa que ideologicamente definia sua identidade. Harvard era inicialmente uma escola de teologia, desdobrando em seguida suas atividades nas áreas do direito e das ciências. John Hopkins, já no século XIX, se bem que pretendesse desenvolver primordialmente o ensino médico e os estudos literários, também devia se manter fiel à orientação da confissão presbiteriana.

O desenvolvimento econômico norteamericano que se seguiu à independência; a ocupação progressiva das terras a oeste e o contraste entre o Norte e o Sul que tem seu clímax durante a juventude de PEIRCE como a guerra de secessão, provoca- 
SILVEIRA, L.F.B. da - Aprender versus ensinar: Charles Sanders Peirce e a universidade americana dc final do século XIX. Trans/Form/Ação, São Paulo, 5: 77-84, 1982.

ram, durante o século XIX, mudanças sociais e políticas que levaram o país a tomar uma fisionomia bastante diferente da que apresentava ainda no final do século anterior. Provocaram deslocamentos de pólos de hegemonia que profundamente atingiram as comunidades mais tradicionais. Massachusetts, que constituiu durante longos anos o maior centro político, econômico e cultural, perdia para $\mathrm{New}$ York, sua hegemonia. Mais ainda, a autosuficiência e a autonomia política das diversas colônias da costa leste que se pretendiam preservadas com a forma federativa que assumiu a Nação com a Independência, começavam a ser suplantadas pela necessidade de se implantar um programa unificado de desenvolvimento econômico que, sobretudo depois da guerra civil, só se poderia efetivar sob o comando do poder federal.

No âmbito da instituição universitária e do ensino em geral, tais mudanças se fizeram sentir, provocando nos centros mais tradicionais reações de nítido conservadorismo ao nível do ensino e o aprof undamento dos privilégios elitistas de sua clientela. Tal reação tentava enfrentar o surgimento de uma estrutura de ensino que visava formar mão-de-obra especializada para as exigências da expansão econômica e que, por conseqüência, abria os estudos superiores a camadas mais amplas e heterogêneas da população. A Universidade de Harvard é o caso exemplar da instituição que pretende guardar seus traços elitizantes $\left({ }^{\mathrm{C}}\right)$ no que contrasta com o ensino em New York mas sobretudo com o programa federal de interiorização do ensino superior de natureza primordialmente técnica. Prometia, com ef eito, o governo da União, através do Morrill Act de 2 de julho de 1862 (4, p.210-211), doar terras aos Estados e Territórios para a construção de "colleges" dedicados ao ensino da agricultura e das artes mecânicas, sem entretanto excluir " “... outros estudos científicos e clássicos aí incluídas as táticas militares, .... a fim de promover a educação liberal e prática das classes industriais nos diversos desempenhos e profissões na vida."

John Hopkins, mesmo tendo sido fundada posteriormente a esta resolução federal, surge como uma universidade clássica. Os fundos para sua sustentação são doados pelo rico e pouco culto comerciante que lhe dá o nome e suas atividades são vigilantemente supervisionadas pelo clero presbiteriano.

PEIRCE pertenceu desde o berço à elite de Harvard, não que pertencesse à burguesia de Boston mas por ser seu pai, Benjamin PEIRCE, reconhecido professor da Universidade. Lá formou-se em física e química e iniciou seu trabalho de docência e pesquisa. Antes dos estudos universitários, recebeu a educação clássica da época, onde predominava o ensino em casa sobre as atividades escolares. Com a orientação de seu pai, adquiriu o hábito do estudo científico e filosófico, o qual aprof undará durante toda sua vida.

Se tivesse permanecido um mero cientista, talvez não viesse a se incompatibilizar tão profundamente com a Instituição. Sua formação filosófica, indissoluvelmente ligada à atividade científica, fêlo adotar em filosofia as exigências teóricas e experimentais que davam consistência à física, à química e, em sua concepção, à própria matemática. Recusou qualquer elaboração que não permitisse verificação experimental e que, constituindo-se num..."balbucio sem sentido - com uma palavra sendo definida por outras palavras, e estas por outras ainda, sem que nunca se chegue a uma concepção real ou num absurdo total"... fosse fonte de intermináveis mal-entendidos e controvérsias que tem feito da mais elevada das ciências positivas (a metafísica) um mero divertimento de intelectos inúteis, uma espécie de jogo de xadrez - tendo por finalidade um prazer inútil e por método, a leitura de um livro"' (3, V, 423). 
SILVEIRA, L.F.B. da - Aprender versus ensinar: Charles Sanders Peirce e a universidade americana dc final do século XIX. Trans/Form/Ação, São Paulo, 5: 77-84, 1982.

Recusou também reduzir a filosofia ao empirismo que desqualifica a instância específica do pensamento. Afirma, ao contrário, a necessidade e a realidade da produção intelectual. Seus produtos - o significado e o objeto - são dotados de um caráter de estrita generalidade, irredutível a qualquer fato, sensação ou ação particular $(3, \mathrm{~V}, 422-434)$.

Deste modo, confronta-se com os metafísicos e com os positivistas, reprovando em ambos um nominalismo de base que joga com as palavras e esvazia o conceito de seu estatuto essencial, como realização genuína do pensamento e como programa - sob a forma de hábito - de uma conduta autocontrolada (3, V, 5965).

Exige do filósofo a atitude, do experimentalista para quem..."qualquer asserção que se lhe faça, ele a entenderá como significando que, se uma dada prescrição para um experimento pode alguma vez ser efetivada, resultará uma experiência de uma dada descrição, ou então ele não verá sentido algum naquilo que se lhe está dizendo."' (3, V, 411). Imbuiu-se, no laboratório, deste rigor e humildade de atitude mas não desacreditou do fazer filosófico. Reconheceu-o passível de verificação no nível que lhe é específico, assim como necessário para fundamentar em última instância as próprias questões que o pensamento científico levanta. A confiabilidade no fazer filosófico cresceu quando, na leitura de pensadores tais como KANT, BERKELEY e SPINOSA, ..."deparou-se com fluxos do pensamento que lembravam os modos do pensar no laboratório"' (3, V, 412).

Nesta perspectiva, destitui-se a filosofia de qualquer pretensão de dogmatismo ou de subjetivismo. Rejeita-se igualmente um transcendentalismo que conferisse a uma razão teórica e, muito mais, a uma razão prática, qualquer instância “a priori" capaz de dotar seus juízos ou suas idéias de "necessidade e universalidade estritas". Todo pensamento é conjectural e está sujeito ao falseamento, mesmo quando argumenta apoditicamente. É porém, dotado de generalidade na medida em que se constitui para a razão num hábito de conduta autocontrolada. Tal hábito determinará para o futuro a interação do sujeito racional com o mundo da experiência e sobretudo enriquecerá tendencialmente a representação desse mundo e, por conseqüência, da própria consciência.

Estruturando a conduta, o pensamento é efetivo. Não há oposição entre o geral e o real; entre o racional e o experimental; entre a atinência à verdade e a intrínseca falseabilidade.

O pensamento é verdadeiro quando a asserção que o constitui fundamenta a crença independentemente das circunstâncias particulares de sua enunciação ou dos interesses e idiossincrasias dos sujeitos emitentes. A verdade do pensamento não o leva a perder, contudo, o caráter histórico e empírico; permanece passível de falseamento pela experiência e contestável por novas hipóteses. A dúvida pode abalar a crença, e a busca da verdade pode exigir novas hipóteses, maior clarificação dos conceitos e uma nova estratégia de verificação. O pensamento é, de fato e de direito, um processo.

Não tem sentido falar de Verdade e Falsidade sem fazer referência à crença como hábito geral e à dúvida como quebra deste hábito. Não se trata de opor um particularismo subjetivo, mesclado quase necessariamente de dimensões psicológicas, a um ontologismo que hipostasiasse seus conceitos ou, ainda, suas Idéias. Trata-se de uma posição filosófica, em sentido estrito, distinta de qualquer generalização de ciências "especiais", as quais estruturam classes particulares de fenômenos segundo leis específicas. Por ser Filosofia, e não mera especulação, refere-se à conduta ef etiva do homem enquanto este age racionalmente $(3, \mathrm{~V}, 416-435)$.

Para PEIRCE, porém, o método de estabelecimento da crença, instaurado pe- 
SILVEIRA, L.F.B. da - Aprender versus ensinar: Charles Sanders Peirce e a universidade americana do final do século XIX.

Trans/Form/Ação, São Paulo, 5: 77-84, 1982.

lo proceder da ciência, e que é o único que deve ser procurado pela filosofia, não é o único que deve de fato prevalecer na sociedade. Somente ele, no entanto, aprofunda o autocontrole da conduta e pode, de si, corrigir-se em vista do alcance da verdade. Em 1877, no artigo intitulado $A$ Fixação da Crença (3, V, 358-387), são apresentados também o método da tenacidade, pelo qual o sujeito fixa-se pela vontade na admissão de uma verdade e recusa-se a admitir alternativas, e 0 método da autoridade, pelo qual uma instituição impõe dogmaticamente enunciações como verdadeiras e exclui de seu seio aquele que não as admite. Apoiada neste método, a humanidade sustentou suas crenças religiosas e construiu monumentos de incontestável significação. Menos perfeitos do que o método da investigação científica da verdade, os dois outros são, no entanto, necessários para a manutenção da conduta humana, sobretudo no que, sendo vitalmente importante - ou imprescindível para a manutenção da vida individual e social - não pode se submeter ao rigor da elaboração conceitual.

A ciência e em particular a filosofia, se bem que possam estender seu domínio de investigação indefinidamente e ter por objeto o cotidiano (3, I, 284-287), apresentam exigências tais de elaboração que as impedem de cobrir todos os aspectos da sustentação da vida e, sobretudo, de autorizar com suas credenciais as crenças que só podem se sustentar pela tenacidade ou pela força da autoridade e do magistério. Não cabe aos cientistas e aos filósof os impor dogmaticamente suas asserções (3, I, 8-9), como não se legitima que teólogos e doutrinadores queiram encobrir suas proposições com os atributos próprios das asserções científicas e filosóficas, ou utilizar uma argumentação emprestada da filosofia para sustentar verdades de fé ou de moral $(3, \mathrm{I}, 620)$.)

A filosofia e a ciência são fundamentalmente hipotéticas, sujeitas à verificação e ao falseamento. A religião, a moral e a procura dos meios imediatamente essenciais para a manutenção da vida exigem uma determinação impossível de se submeter a tais cauções. Por via mediata e sem sucesso previsível, a filosofia e a ciência podem certamente contribuir para esclarecer a consciência e firmar a conduta mesmo naquilo que concerne a tais domínios, mas não podem recobrir seus preceitos (3, I, 616-620).

É, com efeito, no confronto desta postura, à qual PEIRCE permaneceu absolutamente fiel, com o papel que pretendem os teólogos de Harvard e de John Hopkins conferir ao estudo da filosofia, que o desentendimento entre o filósofo e a Instituição tornou-se decisivo, tendo, certamente, constituído o motivo mais profundo para seu afastamento da Universidade. Dominadas por uma preocupação confessional e adotando uma atitude defensiva à liberalização do ensino e da cultura, que progressivamente vai se impondo na sociedade, as Universidades pretendem subjugar a filosofia à imposição da religião e da moral, constituindo-a num instrumental apologético.

A proposta evolucionista de DARWIN que surgia naquele momento e que atraía a atenção de cientistas e filósofos - entre eles, PEIRCE - fazia convergir os olhares dos defensores da ortodoxia para controlar as propostas e denunciar, ao primeiro sinal, um ateísmo e um imoralismo latentes. Thomas HUXLEY, famoso médico inglês, não se livrou do ataque dos teólogos presbiterianos ao pronunciar a aula inaugural da Universidade de John Hopkins. Ele era um defensor da teoria da evolução. Cabia, com efeito, às autoridades universitárias evitar a defesa das doutrinas suspeitas: PEIRCE, dez anos depois do episódio com HUXLEY, não se livrou deste controle $(6, p .1427-$ 1431).

Exigindo da filosofia que somente visasse e fizesse progredir a "Vontade de Aprender (The Will to Learn) e que não impusesse em momento algum uma ver- 
SILVEIRA, L.F.B. da - Aprender versus ensinar: Charles Sanders Peirce e a universidade americana do final do século XIX. Trans/Form/Ação, São Paulo, 5: 77-84, 1982.

dade como definitivamente adquirida; assumindo com disposição e interesse as hipóteses mais audazes do evolucionismo e das demais teorias científicas de seu tempo, não para afirmá-las dogmaticamente ou para ceder a um ecletismo, mas para desenvolvê-las e comprová-las pela exigência da verdade, PEIRCE não podia ser aceito pelo conservadorismo tradicional.

O filósofo colocava toda a ênfase na disciplina intelectual e no rigor lógico das hipóteses, da dedução de suas implicações e na estrita verificação experimental das asserções. Opunha-se a qualquer utilitarismo, entrando em conflito com um ensino e uma pesquisa pretensamente científicos mas, de fato, submissos a interesses de outra ordem. PEIRCE nunca aceitou a redução do racional a um estatuto de mero instrumento tecnológico ou apologético.

A ciência e a filosofia constituem-se em processo árduo, contínuo e exigente de trabalho intelectual e, quando necessário, manual. PEIRCE expressa sua preocupação, mesmo com rasgos de ironia, com uma Universidade, que, sob a capa do ensino da ciência e da filosofia, admitia constituir-se numa mera etapa para o sucesso material e simbólico da elite social da presunçosa comunidade de Massachusetts. Resguardada pela fama de uma longa tradição, Harvard, no julgamento do filósofo, corria o risco de ludibriar o povo americano, que dela esperava o encaminhamento rigoroso de soluções para os graves problemas defrontados (3, I, 17; $\mathrm{V}$, 585).

Com pesar, PEIRCE expressa sua suspeita de tal descaminho de uma Instituição que o viu nascer e na qual se formou. Acusa-a, assim como a toda Universidade americana, do que a seus olhos é a maior deformação que uma escola pode sofrer: não se constituir numa casa de aprendizado mas numa casa de ensino. Pois as duas atitudes - a de aprencler e a de ensinar - são, ao seu dizer,... "quase irreconciliáveis". "Para que o coração to- do do homem possa estar voltado a ensinar, ele deve estar totalmente imbuído da importância vital e da verdade absoluta daquilo que ele deve ensinar; a fim de que, no entanto, alguém tenha algum sucesso em aprender, deve ele estar penetrado com um sentido da insatisfação de sua presente condição de conhecimento. E, como não é o homem convencido de sua própria retidão que pode levar as multidóes ao sentido do pecado, mas o homem que está profundamente convencido que ele mesmo é um pecador, e que é somente por um sentido do pecado que os homens podem escapar de sua servidão também não é o homem que pensa tudo saber, que pode levar outros homens a sentir a necessidade de aprender, e é somente um profundo senso de que é miseravelmente ignorante que pode estimular alguém a avançar no estafante caminho do aprender.' $(3, \mathrm{~V}, 583)$.

E assim pode PEIRCE, falando em Harvard longos anos depois de ter-se dela afastado, concluir sua grave advertência: "Isto é porque, no meu humilde modo de apreender, só pode parecer que aqueles admiráveis métodos pedagógicos, pelos quais os professores americanos são tão distinguidos, produzem muito pouca conseqüência além da que traz o talhe de seus casacos, pois eles seguramente nada são se comparados com a febre de aprender, que deve consumir a alma do homem, que deve infectar outros com a mesma aparente doença." $(3, \mathrm{~V}, 583)$.

Admite em um texto dois anos anteriores, Liçð̃es de História das Ciências, (3, I, 76), que uma Universidade, como a Universidade de Paris no período medieval,... "imponha um padrão oficial de verdade e olhe com olhar severo todos que a questionarem" sem deixar de se constituir num centro de estudo e aprendizado, e venha a produzir grandes bens intelectuais para a civilização. Trata-se, no entanto, do respeito ao modo de fixação da crença exigido pelas diferentes áreas do saber e da conduta humana. No que é de 
SILVEIRA, L.F.B. da - Aprender versus ensinar: Charles Sanders Peirce e a universidade americana do final do século XIX.

Trans/Form/Ação, São Paulo, 5: 77-84, 1982.

fé, prevalece, com ef eito, o argumento de autoridade; o que é da ciência exige a estrita investigação. É a confusão dos critérios de sustentação da crença e é a prática de tal confusão pela Universidade norteamericana que se tornam objeto da denúncia peirceana e impossibilitam a presença do filósofo nos quadros acadêmicos.

William JAMES, que sempre guardou fiel admiração por PEIRCE e o auxiliou constantemente com convites para cursos e conferências e mesmo pecuniariamente, lamentava ainda em 1869 ser quase impossível a PEIRCE realizar o trabalho docente, embora fosse urgente a necessidade de alguém que..." tanto era capaz de devotar as forças de sua vida à lógica e à metafísica, para 'salvar', no país, os homens ortodoxos' (2, p. 16).

A volta ao ensino ia se tornando, contudo, cada vez mais irrealizável e disto PEIRCE tem plena consciência. Nem mesmo publicar consegue, pois não cumpre os prazos exigidos pelos editores. Escreve muito e morre no quase total isolamento. Em seus escritos fica uma contribuição para o pensamento que é a grande obra coletiva de produção da verdade. Cabe ao futuro avaliá-los; ao autor cabe testemunhar a honestidade com que os produziu:

"O desenvolvimento de minhas idéias foram o trabalho de trinta anos. Não sabia se um dia as publicaria, seu amadurecimento parecia demasiado lento. Chegou, afinal, o tempo da colheita, e esta me parece selvagem. Mas não sou eu, naturalmente, que devo emitir o julgamento. Também não é você, leitor individual: cabe à experiência e à história emitilo.

Durante anos, no curso desse processo de amadurecimento, costumava eu próprio reunir minhas idéias sob a designação de falibilismo, e, com ef eito, o primeiro passo em direção à descoberta é saber que você não sabe satisfatoriamente; de tal modo que nenhum mal pode tão seguramente reter qualquer crescimento intelectual do que o mal da presunção; e noventa e nove entre quaisquer cem boas cabeças são reduzidas à impotência por tal doença - para cuja erupção elas estão espantosamente desprevenidas.

Em verdade, toda minha filosofia sempre me pareceu desenvolver-se a partir de um contrito falibilismo combinado com um desejo intenso de descobrir coisas novas..."' $(3, I, 14)$.

\section{NOTAS}

a) Charles Sanders PEIRCE (18391914) foi um dos mais sólidos filósofos norte-americanos. Formado em Física e Química pela Universidade de Harvard, destacou-se nos estudos de matemática (teoria da probabilidade), de lógica (desenvolvimento da álgebra de BOOLE e formulação da lógica dos grafos existenciais) e, sobretudo, da filosofia das ciências (teoria dos argumentos abdutivos, dedutivos e indutivos). Fundador, universalmente conhecido, do Pragmatismo norte-americano, tem seu nome associado à formulação de uma das mais originais e bem elaboradas teorias gerais do signo: a Semiótica peirceana.

b) Diante das profundas transformações que sofria a sociedade norteamericana e, em seu seio, os estudos superiores, a Universidade de Harvard, sob a direção de Charles ELIOT, conheceu um processo de reorganização em 1890. Sob a influência de LOWELL, tentava conter a corrida para a obtenção em larga escala do título doutoral (Ph. D) a fim de preservar um caráter mais fluente das atividades acadêmicas e a valorização dos estudos clássicos. Os resultados desta tentativa de modernização estrutural, conjugada com a manutenção de objetivos tradicionais, não parecem ter sido muito satisfatórios e é sobre eles que certamente incidem as críticas elaboradas por PEIRCE, as quais o presente texto pretende expor $(1$, p. 9 16). 
SILVEIRA, L.F.B. da - Aprender versus ensinar: Charles Sanders Peirce e a universidade americana do final do século XIX. Trans/Form/Ação, São Paulo, 5: 77-84, 1982.

SILVEIRA, L.F.B. da - Learning versus teaching: Charles Sanders Peirce and the American university at the end of the XIX Century. Trans/Form/Ação, São Paulo, 5: 77-84, 1982.

ABSTRACT: For Charles Sanders Peirce (1838-1914), the criterion for the intellectual work and for the conduct of the life of a thinker was absolute rigor in the construction of concepts and strict experimental verification - this outlook caused a complete separation of scientific and philosophical work from any apologetic function. The view that all knowledge of the world of experience and even the knowledge elaborated by Mathematics is intrinsically probable and fallible opposed every and any dogmatism and even the "a priori" of the Kantian tradition. The interest for the evolutionary theory and the unshakable coherence of Pierce's philosophy and attitudes as a professor and a researcher arose strong resistance in the university and editorial world of his time. At a time of serious crises in the North-American university which came as a consequence of the political and economic developments after the Civil War (1861-1965), Peirce's firm position certainly brought about his dismissal from Harvard and John Hopkins Universities, as it also made it difficult for him to publish and it also contributed to his total isolation in the last years of his life.

KEY-WORDS: Charles Sanders PEIRCE; Harvard University; John Hopkins University; Morrill Act; Thomas Huxey; pragmatism; fallibility; evolucionism; philosophy; university teaching.

\section{REFERENCIAS BILIOGRÁFICAS}

1. BERELSON, B. - Graduate Education in the United States. New York, McGraw-Hill, 1960.

2. FEIBLEMAN, J.K. - An introduction to the philosophy of Charles S. Peirce; foreword by Bertrand Russel. Cambridge, M.I.T. Press, 1946, reimp. 1970.

3. HARTSHORNE, C. \& WEISS, P. eds. Collected papers of Charles Sanders Peirce. Cambridge, The Belknap Press of Harvard Univ. Press. 1932, reimp. 1974. v. 1-4.
4. MILLER, W. - Readings in American values; selected and edited from Public Documents of the American Past. Englewood Cliffs, Prentice-Hall, 1964.

5. NAGEL, E. - Review. Scientific American, 200:1455, 1959.

6. SEBEOK, T.A. - Iconicity. $M L N, 91, \mathrm{n} .^{\circ} 6$, 1976.

7. THAYER, H.S. - Meaning and action; a study of American Pragmatism. Indianapolis, Bobbs Merrill, 1973. 